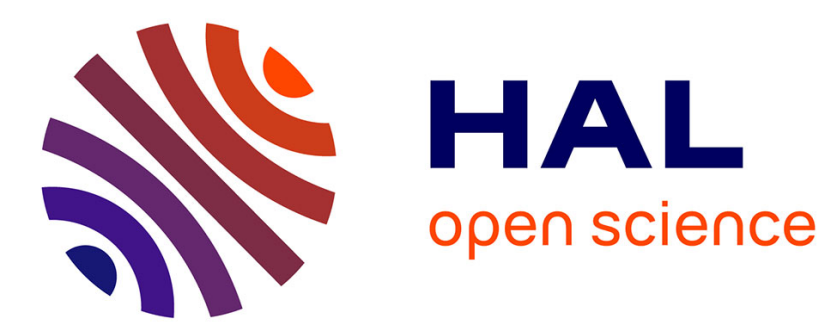

\title{
Neonatal brain MRI: how reliable is the radiologist's eye?
}

\author{
B Morel, G Antoni, Jp Teglas, Isabelle Bloch, C Adamsbaum
}

\section{To cite this version:}

B Morel, G Antoni, Jp Teglas, Isabelle Bloch, C Adamsbaum. Neonatal brain MRI: how reliable is the radiologist's eye?. Neuroradiology, 2015, 10.1007/s00234-015-1609-2 . hal-01237898

\section{HAL Id: hal-01237898 \\ https://hal.science/hal-01237898}

Submitted on 3 Dec 2015

HAL is a multi-disciplinary open access archive for the deposit and dissemination of scientific research documents, whether they are published or not. The documents may come from teaching and research institutions in France or abroad, or from public or private research centers.
L'archive ouverte pluridisciplinaire HAL, est destinée au dépôt et à la diffusion de documents scientifiques de niveau recherche, publiés ou non, émanant des établissements d'enseignement et de recherche français ou étrangers, des laboratoires publics ou privés. 


\title{
Neonatal brain MRI: How reliable is the radiologist's eye?
}

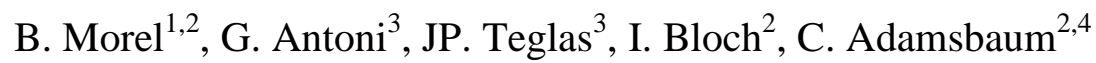 \\ ${ }^{1}$ MD, Pediatric radiology, A. Trousseau Hospital APHP, Paris, France \\ ${ }^{2}$ Mines TelecomInstitute, Telecom ParisTech, CNRS LTCI, Paris, France \\ ${ }^{3}$ MD, INSERM, CESP Centre for Research in Epidemiology and Population Health, U1018, \\ Reproduction and Child Development, F-94807, Villejuif, France; Paris-Sud University, \\ UMRS 1018, F-94807, Villejuif, France \\ ${ }^{4}$ MD, Pediatric Radiology Department, Bicêtre Hospital APHP, Kremlin-Bicêtre, APHP, \\ Paris Sud University, Faculty of Medicine, France
}

Acknowledgement: the authors thank Nina Friedman for English language assistance.

\section{Corresponding author:}

Baptiste Morel, baptiste.morel@aphp.fr

A. Trousseau Hospital APHP, 26 avenue du Dr Arnold Netter, 75012 Paris

Phone number: 0033171738756 Fax number: 0033144736511

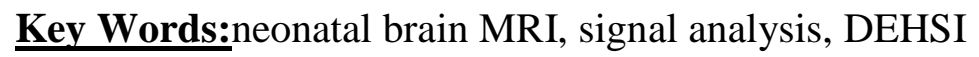

Funding Source: No funding was secured for this study.

Financial Disclosure: The authors have no financial relationships relevant to this article to disclose.

Conflict of Interest: The authors have no conflict of interest to disclose.

Ethical Standards and Patient Consent: 
We declare that all human studies have been approved by the local ethics committee and have therefore been performed in accordance with the ethical standards laid down in the 1964 Declaration of Helsinki and its later amendments. We declare that all patients gave informed consent prior to inclusion in this study.

\section{Technical Note}

\section{Introduction}

Perinatal imaging plays a major role in the assessment of human brain development. Magnetic resonance imaging (MRI) is considered the most powerful tool for exploring the anatomy and signal intensity of the neonatal brain. But reliably assessing the shape, volume and signal intensity of cerebral structures - particularly the white matter (WM) - is a challenge. Unlike in CT imaging, there is no MRI equivalent to the Hounsfield scale to help radiologists quantify and compare signal intensities.

Newborns differ from older populations by their smaller brain size and an inverted white/grey matter contrast on MRI. Brain maturation is a dynamic process that can be charted in vivo via the development of myelination features, which have been described exhaustively using MRI[1,2]. Grey and white matter components can be analyzed in two complementary ways, based on either morphology or signal intensity. Each radiologist has his or her own way of looking at this exam, as illustrated by the numerous scoring systems for determining the nature and extent of MR imaging abnormalities[3]. The premature newborn brain is a peculiar entity - no longer fetal, but not yet adult.Subjective analysis can be an issue, as demonstrated recently by the debate overdiffuse excessive high signal intensity (DEHSI).DEHSI was initially described as regions of "high signal intensity in the periventricular frontal and parieto-occipital area on T2-weighted images, $[4,5]$ and has been reported in up to $80 \%$ of very premature infants at term-equivalent age[6].Though its prognostic value is under 
debate[7-12], DEHSI are now considered a development-related imaging pattern [8]. This finding can influence medical decisions when associated with other abnormalities such as white matter punctate lesions, in which case it may then have significant ethical implications. Our purpose, however, is to focus on the analysis of white matter signal intensity in T2weighted MRI to evaluate the reliability of the radiologist's eye, independent of any associated abnormalities.

\section{Materials and Methods}

\section{Data acquisition}

We used axial T2-weighted TSE images from 60 different premature newborns (born between 28 and 29 weeks of gestation) whose clinical status, transfontanellar ultrasound and electroencephalogram were all normal. Infants underwent MRI after feeding, swaddling and placement of ear protection. Parents gave their informed consent for medical use of the MR images. The images were acquired at term-equivalent age (between 39 and 40 weeks of gestation) using routine protocols on a Philips $1.5 \mathrm{~T}$ Achieva system with an 8-element head coil. The acquisition parameters were as follows: $\mathrm{TR}=3750 \mathrm{~ms}$; TE=110 ms; Turbo-factor = 16. The MRI slices were acquired on a 512 x 512 pixel matrix, covering the field of view, without interpolation, with a resolution of 2.560pixelsper millimeter (pixel size $=0.39 \times 0.39$ $\mathrm{mm})$ and slice thickness $=4 \mathrm{~mm}$.Signal intensity analyses were performed with ImageJ software[13].

\section{Observers}

Measurements were performed by three people: two senior radiologists (Observer 1 and Observer 2, with three and twenty years of experience in pediatric neuroimaging, respectively) and one senior computer science researcher (Observer 3, with twenty years of 
experience in medical imaging). The rationale for using this sample of readers was to try to evaluate the role of experience in the specific analysis of white matter.The computer science researcher was used as a "non-clinical" control, who would not be influenced by the clinical context or the particularity of newborn brain MRI contrast.

\section{White matter signal intensity analysis}

The three readers compared the relative signal intensity of different circular regions of interest (ROI).In all cases, the ROIs were defined by one of the senior radiologists in the same areas corresponding to the frontal and occipital periventricular white matter - before each experiment session. The viewing parameters were kept constant for all of the images to avoid any change during or between experiments.

Comparison1 was between the highest signal intensity of the periventricular frontal white matter and the subcortical frontal white matter (Figure 1). Comparison2 was between the same highest signal intensity of the periventricular frontal white matter and the subcortical occipital white matter (Figure 1). These two comparisonsweredone twice, four weeks apart, to test the intra-observer variability.

The following semi-quantitative classification was used:

$-1=$ periventricular frontal white matter displays lower signal intensity than the subcortical frontal white matter;

$0=$ no difference in signal intensity;

$1=$ periventricular frontal white matter displays slightly higher signal intensity than the subcortical frontal white matter 
$2=$ periventricular frontal white matter displays much higher intensity signal than the subcortical frontal white matter

\section{Statistical analysis}

Intra- and inter-observer agreement on the white matter signal intensity comparisons were assessed using Fleiss' kappa coefficient, where agreement is considered "fair" if $\kappa$ is between 0.21 and 0.40 , "moderate"if $\kappa$ is between 0.41 and 0.60 , "substantial" if $\kappa$ is between 0.61 and 0.80 , and "almost perfect"if $\kappa$ is between 0.81 and 1 . Statistical analysis was performed using R software[14].

\section{Results}

\section{4-category classification system:}

The overall inter-observerFleiss' kappa agreement was moderate for the first comparison, between the periventricular frontal and subcortical frontal white matter signal (Table 1)

The overall inter-observerFleiss' kappa agreement was fair to moderate for the second comparison, between the periventricular frontal and subcortical occipital white matter signal (Table 1).

The intra-observer Fleiss' kappa agreement was fair for two observers and poor to fair for the third (Table 2).

\section{3-category classification system:}

We further analyzed our results to investigate the impact of distinguishing grades 1 and 2 by merging them into one category. The resulting Fleiss' kappa agreement is shown in Tables 3 and 4 . 
The overall interobserver Fleiss' kappa agreement was fair to substantial for the first comparison, between the periventricular frontal and subcortical frontal white matter signal.

The overall interobserver Fleiss' kappa agreement was fair to substantial for the second comparison, between the periventricular frontal and subcortical occipital white matter signal.

The intraobserver Fleiss' kappa agreement was fair to moderate for two observers and moderate for the third.

\section{Discussion}

Brain MRI provides fine details of the newborn brain using multiple sequences. Recent debate on the significance of DEHSI in the white matter[4, 5] of term-equivalent age premature infants deserves special attention for ethical reasons.In our experience, however, the assessment of such white matter "high signal intensity" issomewhat subjective, and interobserver variability may be underestimated. While it has been shown that the detectability of low-contrast lesions can be affected by retinal photoreceptor light adaptation [15], to our knowledge there is no published work evaluating observer variability in interpreting newborn brain MRI. The scale chosen for the comparison is similar to that used in previously published studies $[11,16]$.Our results show fair to substantial intra- and inter-observer agreement in the analysis of white matter signal intensity. If we simplify our scale by combining grades 1 and 2 to reduce subjectivity, we see a slight improvement in the inter- and intraobserver Fleiss' kappa agreement, as might be expected. But the overall results are similar, highlighting the difficulty of visual intensity signal analysis, whatever the scale used.Though the difficulties in interpreting Kappa statistics are well known, they are still commonly used to quantify interobserver agreement, even in recent publications [3, 5]. In our study, all experiments were done twice under strictly identical viewing conditions by all observers simultaneously to avoid any bias. We were thus able to study inter- and intraobserver variability and obtain 
more robust results. One previous study focused specifically on the appearance of DEHSI on different T2-weighted sequences (Fast Spin Echo and Single Shot FSE)[17], and concluded that the appearance of DEHSI on MR images following preterm birth is highly subjective, with slightly low intra- and inter-observer agreement (intraclass correlation of 0.04). Though our results showed better agreement foranalysis of WM intensity, this is an important limitation of the visual assessment task, and one we should be aware of. Another difficulty is the subjective identification of the highest WM signal intensity, which might explain the moderate inter-observer agreement. A great deal of caution is needed when drawing conclusions about WM signal intensity, and these results highlight the need for a semiautomatic tool to make signal intensity analysisin the neonatal brain more objective.

\section{Conflict of Interest statement:}

BM, GA, JPT, IB and CA have no conflict of interest to disclose.

\section{References}

1. Girard N, Raybaud C, du Lac P (1991) MRI study of brain myelination. J Neuroradiol 18:291-307.

2. Barkovich AJ (1998) MR of the normal neonatal brain: assessment of deep structures. AJNR Am J Neuroradiol 19:1397-1403.

3. Kidokoro H, Neil JJ, Inder TE (2013) New MR imaging assessment tool to define brain abnormalities in very preterm infants at term. AJNR Am J Neuroradiol 34:2208-2214.

4. Counsell SJ, Shen Y, Boardman JP, et al. (2006) Axial and radial diffusivity in preterm infants who have diffuse white matter changes on magnetic resonance imaging at termequivalent age. Pediatrics 117:376-386.

5. Counsell SJ, Allsop JM, Harrison MC, et al. (2003) Diffusion-weighted imaging of the brain in preterm infants with focal and diffuse white matter abnormality. Pediatrics 112:1-7. 
6. Dyet LE, Kennea N, Counsell SJ, et al. (2006) Natural history of brain lesions in extremely preterm infants studied with serial magnetic resonance imaging from birth and neurodevelopmental assessment. Pediatrics 118:536-548.

7. Jeon TY, Kim JH, Yoo S-Y, et al. (2012) Neurodevelopmental outcomes in preterm infants: comparison of infants with and without diffuse excessive high signal intensity on MR images at near-term-equivalent age. Radiology 263:518-526.

8. de Bruïne FT, van den Berg-Huysmans AA, Leijser LM, et al. (2011) Clinical implications of MR imaging findings in the white matter in very preterm infants: a 2year follow-up study. Radiology 261:899-906.

9. Woodward LJ, Anderson PJ, Austin NC, et al. (2006) Neonatal MRI to predict neurodevelopmental outcomes in preterm infants. N Engl J Med 355:685-694.

10. Parikh NA, He L, Bonfante-Mejia E, et al. (2013) Automatically quantified diffuse excessive high signal intensity on MRI predicts cognitive development in preterm infants. Pediatr Neurol 49:424-430.

11. Leitner Y, Weinstein M, Myers V, et al. (2014) Diffuse excessive high signal intensity in low-risk preterm infants at term-equivalent age does not predict outcome at 1 year: a prospective study. Neuroradiology.

12. Van't Hooft J, van der Lee JH, Opmeer BC, et al. (2015) Predicting developmental outcomes in premature infants by term equivalent MRI: systematic review and metaanalysis. Syst Rev 4:71.

13. Rasband WS (2008) ImageJ. Httprsbweb Nih Govij

14. Team RC (2012) R: A language and environment for statistical computing. $\mathrm{R}$ Foundation for Statistical Computing, Vienna, Austria, 2012. ISBN 3-900051-07-0

15. Baxter B, Ravindra H, Normann RA (1982) Changes in lesion detectability caused by light adaptation in retinal photoreceptors. Invest Radiol 17:394-401.

16. Calloni SF, Cinnante CM, Bassi L, et al. (2015) Neurodevelopmental outcome at 36 months in very low birth weight premature infants with MR diffuse excessive high signal intensity (DEHSI) of cerebral white matter. Radiol Med (Torino).

17. Hart AR, Smith MF, Rigby AS, et al. (2010) Appearances of diffuse excessive high signal intensity (DEHSI) on MR imaging following preterm birth. Pediatr Radiol 40:1390-1396. 
Table 1:

\begin{tabular}{|c|c|c|c|c|}
\hline \multirow{2}{*}{$\begin{array}{c}\text { Inter-observer Fleiss, } \\
\text { Kappa Agreementwith } \\
\text { 4 class scale }\end{array}$} & $\begin{array}{c}\text { Comparison 1: periventricular } \\
\text { frontal white matter vs. } \\
\text { subcortical frontal white } \\
\text { matter }\end{array}$ & $\begin{array}{c}\text { Comparison 2: } \\
\text { periventricular frontal } \\
\text { white matter vs. } \\
\text { subcortical occipital white } \\
\text { matter }\end{array}$ & \begin{tabular}{c} 
2nd \\
\cline { 2 - 5 }
\end{tabular} & \multicolumn{2}{|c|}{$1^{\text {st }}$ occasion } & $2^{\text {nd }}$ occasion & $1^{\text {st }}$ occasion & $2^{\text {nd }}$ occasion \\
\hline Overall Agreement & $\mathbf{0 . 4 1 4}$ & $\mathbf{0 . 5 9 5}$ & $\mathbf{0 . 6 0 4}$ & $\mathbf{0 . 3 6 8}$ \\
\hline Observer 1/Observer 2 & 0.25 & 0.627 & 0.555 & 0.222 \\
\hline Observer 1/Observer 3 & 0.536 & 0.631 & 0.626 & 0.415 \\
\hline Observer 2/Observer 3 & 0.456 & 0.525 & 0.635 & 0.479 \\
\hline
\end{tabular}

Table 1: Inter-observer Fleiss' Kappa Agreement for the comparisons 1 and 2 with 4 class scale.

Table 2:

\begin{tabular}{|c|c|c|}
\hline $\begin{array}{c}\text { Intra-observer Fleiss' } \\
\text { Kappa Agreement } \\
\text { with 4 class scale }\end{array}$ & $\begin{array}{c}\text { Comparison 1: } \\
\text { periventricular frontal } \\
\text { white matter vs. } \\
\text { subcortical frontal white } \\
\text { matter }\end{array}$ & $\begin{array}{c}\text { Comparison 2: } \\
\text { periventricular frontal white } \\
\text { matter vs. subcortical } \\
\text { occipital white matter }\end{array}$ \\
\hline Observer 1 & 0.211 & 0.213 \\
\hline Observer 2 & 0.1 & 0.301 \\
\hline Observer 3 & 0.366 & 0.402 \\
\hline
\end{tabular}

Table 2: Intra-observer Fleiss' Kappa Agreement for the comparisons 1 and 2 with 4 class scale.

Table 3:

\begin{tabular}{|c|c|c|}
\hline $\begin{array}{c}\text { Inter-observer Fleiss, } \\
\text { Kappa Agreement } \\
\text { with 3 class scale }\end{array}$ & $\begin{array}{c}\text { Comparison 1: periventricular } \\
\text { frontal white matter vs. } \\
\text { subcortical frontal white } \\
\text { matter }\end{array}$ & $\begin{array}{c}\text { Comparison 2: } \\
\text { periventricular frontal } \\
\text { white matter vs. } \\
\text { subcortical occipital white } \\
\text { matter }\end{array}$ \\
\hline
\end{tabular}




\begin{tabular}{|c|c|c|c|c|}
\cline { 1 - 1 } & $1^{\text {st }}$ occasion & $2^{\text {nd }}$ occasion & $1^{\text {st }}$ occasion & $2^{\text {nd }}$ occasion \\
\hline Overall Agreement & $\mathbf{0 . 3 4 4}$ & $\mathbf{0 . 6 2 5}$ & $\mathbf{0 . 7 2}$ & $\mathbf{0 . 4 0 7}$ \\
\hline Observer 1/Observer 2 & 0.169 & 0.667 & 0.732 & 0.276 \\
\hline Observer 1/Observer 3 & 0.587 & 0.7 & 0.732 & 0.461 \\
\hline Observer 2/Observer 3 & 0.155 & 0.506 & 0.696 & 0.494 \\
\hline
\end{tabular}

Table 3: Inter-observer Fleiss' Kappa Agreement for the comparisons 1 and 2 with 3 class scale.

Table 4:

\begin{tabular}{|c|c|c|}
\hline $\begin{array}{c}\text { Intra-observer Fleiss' } \\
\text { Kappa Agreement } \\
\text { with 3 class scale }\end{array}$ & $\begin{array}{c}\text { Comparison 1: } \\
\text { periventricular frontal } \\
\text { white matter vs. } \\
\text { subcortical frontal white } \\
\text { matter }\end{array}$ & $\begin{array}{c}\text { Comparison 2: } \\
\text { periventricular frontal white } \\
\text { matter vs. subcortical } \\
\text { occipital white matter }\end{array}$ \\
\hline Observer 1 & 0.439 & 0.383 \\
\hline Observer 2 & 0.129 & 0.411 \\
\hline Observer 3 & 0.498 & 0.463 \\
\hline
\end{tabular}

Table 4: Intra-observer Fleiss' Kappa Agreement for the comparisons 1 and 2 with 3 class scale.

\section{Figures captions}

Figure 1: Visual comparison of the highest signal intensity between circular regions of interest. Comparison 1 was between the periventricular frontal (A) and subcortical frontal (B) white matter. Comparison 2 was between the periventricular frontal (A) and subcortical occipital (C) white matter at term-equivalent age on T2-weighted axial slices. 


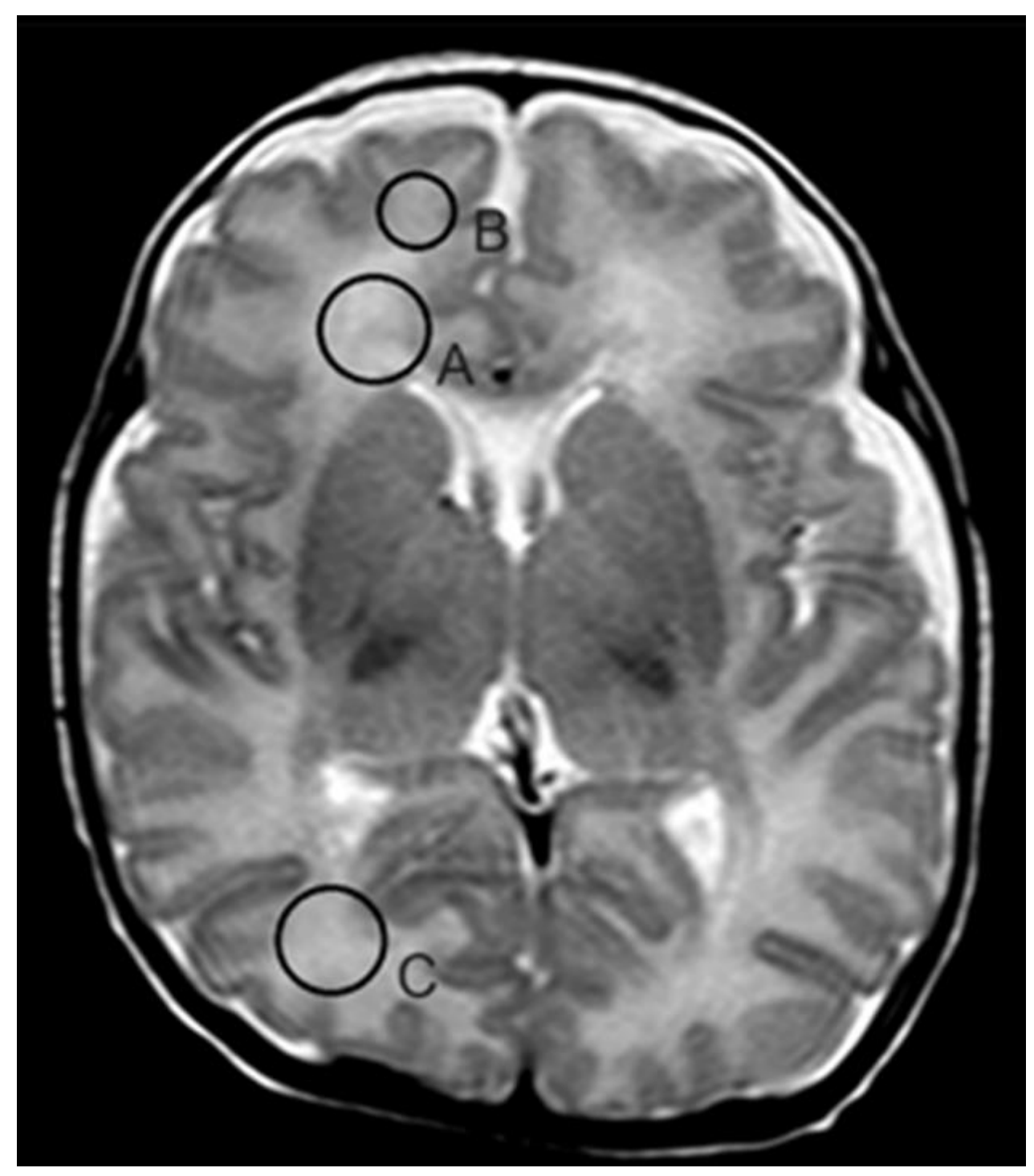

